\title{
Bi-segmentectomy versus wedge hepatic resection in extended cholecystectomy for T2 and T3 gallbladder cancer: A matched case-control study
}

\author{
Hirdaya Hulas Nag, Phani Kumar Nekarakanti, Ashish Sachan, Prithviraj Nabi, Sonam Tyagi
}

Department of Gastrointestinal Surgery, Govind Ballabh Pant Institute of Postgraduate Medical Education and Research, New Delhi, India

Backgrounds/Aims: Extended cholecystectomy (EC) is the mainstay of treatment in most patients with potentially curable gallbladder cancer (GBC). The optimum extent of hepatic resection in EC is debatable.

Methods: This retrospective study was conducted on patients with GBC who received EC from May 2009 to February 2019 . Based on the extent of hepatic resection, patients were divided into ECB (EC involving bi-segmentectomy s4b\&5) and ECW (EC involving wedge hepatic resection) groups. Patients with T1 GBC, T4 GBC, and benign diseases were excluded. Post-exclusion, both groups were matched for $\mathrm{T}$ and $\mathrm{N}$ stage. Matched groups were then compared.

Results: Out of a total of 161 patients who received EC, 86 patients had ECB and 75 patients had ECW. After exclusion and matching, both ECB and ECW groups had 35 patients. Their demographic and clinical profiles were comparable. Surgical blood loss $(p=0.005)$ and postoperative complication rate $(p=0.035)$ were significantly less in the ECB group. For ECB vs. ECW, mean recurrence-free survival (RFS) was 58.2 months vs. 42.3 months $(p=0.264)$ and overall survival (OS) was 61.5 months vs. 43.4 months $(p=0.161)$. On univariate analysis, higher $\mathrm{T}$ and $\mathrm{N}$ stages were associated with poor prognosis. On multivariate analysis, higher $\mathrm{T}$ stage, $\mathrm{N}$ stage, and American Society of Anaesthesiologists grade were associated with poor RFS and OS.

Conclusions: The survival after ECB for T2 and T3 GBC was not significantly superior to that after ECW. However, surgical blood loss and postoperative complications were lower following ECB.

Key Words: Gallbladder neoplasms; Extended cholecystectomy; Radical cholecystectomy; Bi-segmentectomy; Wedge hepatic resection

\section{INTRODUCTION}

Gallbladder cancer (GBC) is the most common malignant disorder of the biliary tract. Operation is the only potential cure available to patients with GBC. Extended (or radical) cholecystectomy (EC) is the standard surgical procedure for most

Received: March 7, 2021, Revised: April 24, 2021,

Accepted: April 26, 2021

Corresponding author: Hirdaya Hulas Nag

Department of Gastrointestinal Surgery, Govind Ballabh Pant Institute of

Postgraduate Medical Education and Research, Room No. 220, Academic

Block, New Delhi 110002, India

Tel: +91-1123234242 (ext. 5220), Fax: +91-1123235702,

E-mail: hirdayanag@gmail.com

ORCID: https://orcid.org/0000-0002-0194-7752

Copyright (C) The Korean Association of Hepato-Biliary-Pancreatic Surgery

This is an Open Access article distributed under the terms of the Creative Commons Attribution Non-Commercial License (http://creativecommons.org/licenses/by-nc/4.0) which on-commercial use, distribution, and reproduction in any medium, provided the original permits unrestricted work is properly cited. patients with T2 and T3 GBC [1]. The extent of hepatic resection in EC has been variable from a few centimetres of gallbladder fossa $(\mathrm{GBF})$ to complete excision of hepatic segment $\mathrm{s} 4 \mathrm{~b} \& 5$ [1-5]. Advocates of hepatic bi-segmentectomy 4 b\&5 in EC believe that microscopic metastatic foci of the GBC may present as skip lesions inside segments $4 \mathrm{~b} \& 5$. Therefore, complete excision of s4b\&s5 is necessary to prevent a recurrence [6-8]. However, two questionnaire surveys have reported no survival advantage with bi-segmentectomy s4b\&s5 for patients with T2 GBC $[9,10]$. Thus, we conducted a matched case-control study to compare outcomes of ECB (EC involving bi-segmentectomy s4b\&5) to those of ECW (EC involving wedge hepatic resection) for patients with T2\&T3 GBC.

\section{PATIENTS AND METHODS}

This matched case-control study was conducted at Govind Ballabh Pant Institute of Postgraduate Medical Education and 
Research, New Delhi, India. Hospital records of patients who were offered EC by single unit from May 2009 to February 2019 were reviewed. Follow-up data were collected up to February 2019. Written informed consent from patient was waived by the institutional committee of ethics [11]. Based on the type of hepatic resection, patients were divided into ECB and ECW groups. Patients with T1 GBC, T4 GBC, or benign diseases were excluded. Post-exclusion, both groups were exactly (1 : 1) matched for $\mathrm{T}$ and $\mathrm{N}$ stages using MedCalc software 19.6.1 (MedCalc Software Ltd, Ostend, Belgium; https://www.medcalc. org; 2020) (Fig. 1). Demographic, clinical, operative, and postoperative parameters of the two groups were then compared.

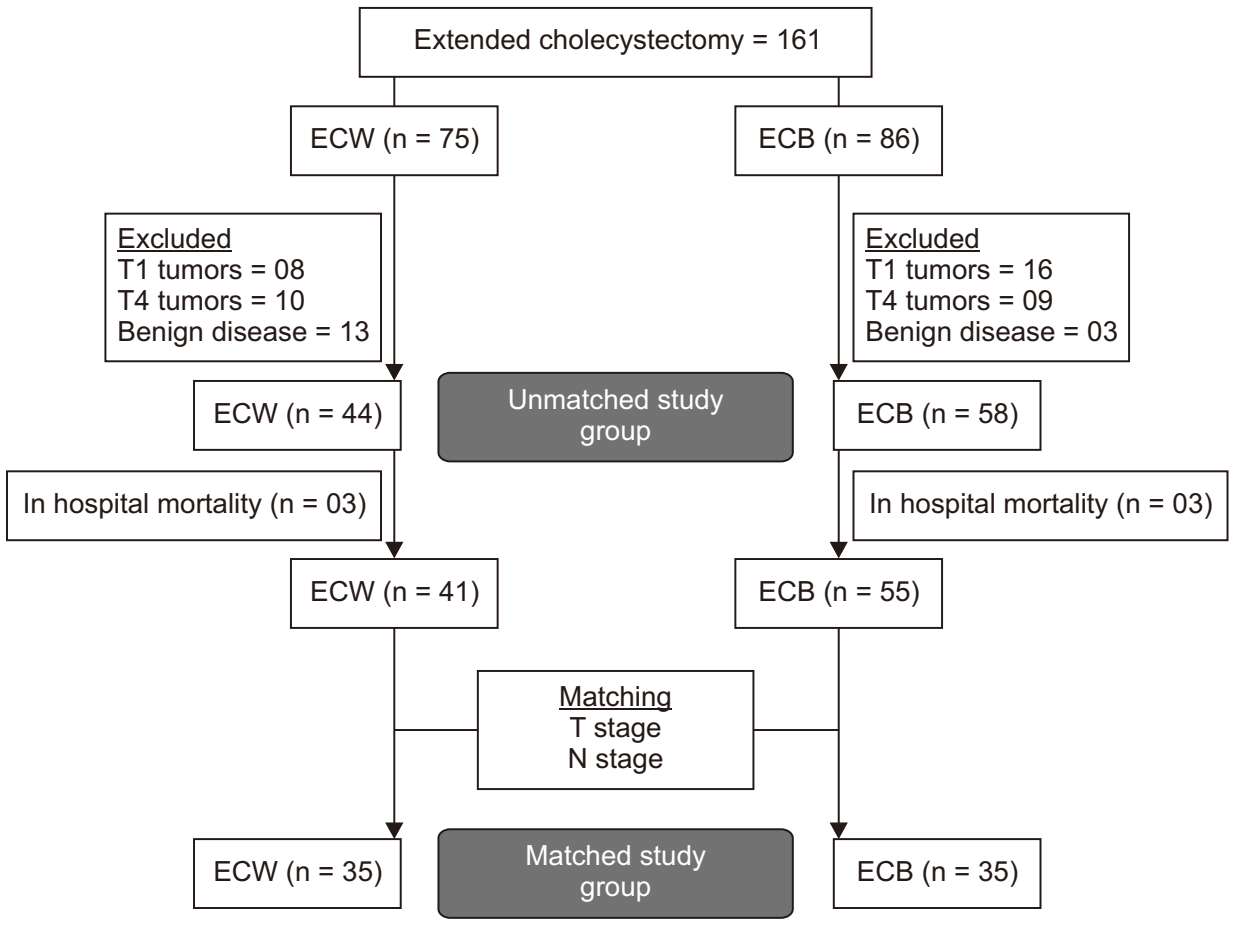

Fig. 1. Flow diagram showing the selection of study subjects. ECB, extended cholecystectomy involving bi-segmentectomy s4b\&5; ECW, extended cholecystectomy involving wedge hepatic resection.

Table 1. Comparison of demographic and laboratory parameters

\begin{tabular}{|c|c|c|c|c|c|c|}
\hline Variable & \multicolumn{3}{|c|}{ Before matching } & \multicolumn{3}{|c|}{ After matching } \\
\hline Age (yr) & $51(43.5-60.0)$ & $50(44-60)$ & 0.794 & $52(42.7-60.0)$ & $49(45-60)$ & 0.737 \\
\hline Sex (female) & $29(65.9)$ & $41(70.7)$ & 0.608 & $25(71.4)$ & $27(77.1)$ & 0.587 \\
\hline ASA grade & & & & & & 0.386 \\
\hline 0 & 0 & $5(8.6)$ & & 0 & $3(8.6)$ & \\
\hline 3 & 0 & $2(3.4)$ & & 0 & $1(2.9)$ & \\
\hline Comorbidity & $6(13.6)$ & $9(15.5)$ & 0.791 & $4(11.4)$ & $5(14.3)$ & 0.723 \\
\hline IGBC & $11(25.0)$ & $13(22.4)$ & 0.761 & $9(25.7)$ & $9(25.7)$ & 1.000 \\
\hline Pre-operative hemoglobin (gm/dL) & $10.9(10-12.1)$ & $11.1(9.5-11.9)$ & 0.633 & $10.8(10.0-11.9)$ & $11(9.0-11.7)$ & 0.462 \\
\hline Pre-operative bilirubin (mg/dL) & $0.8(0.6-1.5)$ & $0.6(0.5-0.9)$ & $0.01 *$ & $0.7(0.6-1.3)$ & $0.6(0.5-0.9)$ & 0.05 \\
\hline
\end{tabular}

Values are presented as median (interquartile range) or number (\%).

ECB, extended cholecystectomy involving bi-segmentectomy s4b\&5; ECW, extended cholecystectomy involving wedge hepatic resection; ASA, American Society of Anaesthesiologists; IGBC, incidental gallbladder cancer.

*Staristically significant $(p<0.05)$. 
The preoperative workup for patients with GBC included clinical history, clinical examination, complete blood counts, biochemistry (renal function tests, liver function tests, international normalized ratio), and tumour markers (carcino-embryonic-antigen and carbohydrate antigen 19.9), ultrasound of the abdomen, contrast-enhanced computed tomography (CECT) of the chest and the abdomen, and endoscopic ultrasound (EUS). Fine needle aspiration cytology was conducted under conventional/EUS guidance if an inoperable disease was suspected on radiological imaging. The American Joint Committee on Cancer (AJCC) 8th classification system was employed. Due to a high prevalence of patients with incidental GBC (IGBC), sub-classification of T2 stage into T2a and T2b was omitted [12]. The severity of postoperative complications was described per the classification proposed by Dindo et al. [13]. Hospital mortality was defined as mortality within 90 days from the operation. ECB was defined as excision of GB plus hepatic segments s4b and 5 plus hepatoduodenal ligament nodes (HDLNs). ECW was defined as en-bloc excision of GB plus two centimetres of tumor-uninvolved liver conforming GBF and HDLNs. Staging laparoscopy was performed through an infra-umbilical endoscopic port. EC was abandoned in patients with confirmed $\mathrm{N} 2$ and M1 metastasis. Laparoscopic ECB was performed as described by Nag et al. [14]. Any involvement of adjacent organs such as common bile duct (CBD), stomach, duodenum, and colon were dealt with $\mathrm{CBD}$ resection, distal gastrectomy, duodenal sleeve resection, and colonic resection, respectively. Adjuvant chemotherapy was given after attaining consensus of surgeon, oncologist, and patient willingness.

\section{Statistical analysis}

Statistical package MedCalc 19.6.1 (MedCalc Software Ltd) was used for analysis and case-control matching. Parametric numerical data are presented as mean \pm standard deviation. Non-parametric numerical data are presented as median (interquartile range). Categorical and ordinal data are presented as percentages. Parametric numerical data were compared with Student's t-test. Non-parametric numerical data were compared with a Mann-Whitney U-test. Chi-square test and Fisher's test were used to compare categorical and ordinal data. Kaplan Mei-

Table 2. Comparison of operation details and postoperative outcome

\begin{tabular}{|c|c|c|c|c|c|c|}
\hline \multirow{2}{*}{ Variable } & \multicolumn{3}{|c|}{ Before matching } & \multicolumn{3}{|c|}{ After matching } \\
\hline & $\mathrm{ECW}(\mathrm{n}=44)$ & $\mathrm{ECB}(\mathrm{n}=58)$ & $p$-value & $\operatorname{ECW}(n=35)$ & $\operatorname{ECB}(n=35)$ & $p$-value \\
\hline Postoperative stay (day) & $8(5-12.5)$ & $6(5-8)$ & 0.158 & $8(5-12.5)$ & $6(5-8)$ & 0.216 \\
\hline Duration of surgery (min) & $300(240-360)$ & $240(200-320)$ & 0.059 & $300(225-357)$ & $270(240-325)$ & 0.748 \\
\hline Blood loss (mL) & $250(200-300)$ & $200(120-200)$ & $0.000^{*}$ & $250(200-300)$ & $200(100-200)$ & $0.005^{*}$ \\
\hline Postoperative complications & $20(45.5)$ & $18(31.0)$ & 0.137 & $14(40.0)$ & $6(17.1)$ & $0.035^{*}$ \\
\hline Clavien-Dindo Grade I/Grade II/Grade III/Grade IV & $5 / 9 / 2 / 0$ & $11 / 1 / 1 / 1$ & $0.032^{*}$ & $3 / 8 / 2 / 0$ & $4 / 0 / 1 / 1$ & $0.046^{*}$ \\
\hline Post-operative bile leak & $11(25.0)$ & $1(1.7)$ & $0.000^{*}$ & $8(22.9)$ & 0 & $0.002^{*}$ \\
\hline T stage & & & & & & 1.000 \\
\hline $\mathrm{T} 2$ & $23(52.3)$ & $31(53.4)$ & 0.906 & $19(54.3)$ & $19(54.3)$ & \\
\hline T3 & $21(47.7)$ & $27(46.6)$ & & $16(45.7)$ & $16(45.7)$ & \\
\hline N stage & & & 0.039 & & & 1.000 \\
\hline NO & $18(40.9)$ & $36(62.1)$ & & $18(51.4)$ & $18(51.4)$ & \\
\hline $\mathrm{N} 1$ & $9(20.5)$ & $12(20.7)$ & & $8(22.9)$ & $8(22.9)$ & \\
\hline $\mathrm{N} 2$ & $17(38.6)$ & $10(17.2)$ & & $9(25.7)$ & $9(25.7)$ & \\
\hline AJCC staging & & & $0.029 *$ & & & 1.000 \\
\hline Stage 2 & $12(27.3)$ & $22(37.9)$ & & $12(34.3)$ & $12(34.3)$ & \\
\hline Stage 3 & $15(34.1)$ & $27(46.6)$ & & $14(40.0)$ & $14(40.0)$ & \\
\hline Stage 4 & $17(38.6)$ & $9(15.5)$ & & $9(25.7)$ & $9(25.7)$ & \\
\hline PNI/LVI positive & $15(34.1)$ & $12(20.7)$ & 0.130 & $13(37.1)$ & $8(22.9)$ & 0.195 \\
\hline Minimum margin (mm) & $8(3-20)$ & $14(8.2-19.5)$ & 0.098 & $9(5-20)$ & $12(8-15)$ & 0.487 \\
\hline Adjuvant chemotherapy & $25(56.8)$ & $34(58.6)$ & 0.855 & $22(62.9)$ & $23(65.7)$ & 0.804 \\
\hline Recurrence & $22(50.0)$ & $15(25.9)$ & $0.013^{*}$ & $16(45.7)$ & $11(31.4)$ & 0.259 \\
\hline Recurrence free survival (mon) & $37.5 \pm 4.9$ & $64.9 \pm 5.1$ & $0.014^{*}$ & $42.3 \pm 5.41$ & $58.2 \pm 6.2$ & 0.264 \\
\hline Overall survival (mon) & $39.0 \pm 4.5$ & $67.0 \pm 4.9$ & $0.008^{*}$ & $43.4 \pm 5.05$ & $61.5 \pm 5.8$ & 0.161 \\
\hline
\end{tabular}

Values are presented as median (interquartile range), number (\%), or mean \pm standard error.

ECB, extended cholecystectomy involving bi-segmentectomy s4b\&5; ECW, extended cholecystectomy involving wedge hepatic resection; AJCC, American Joint Committee on Cancer; PNI, perineural invasion; LVI, lymphovascular invasion.

*Staristically significant $(p<0.05)$. 
er method (log-rank test) and Cox regression method were used for survival analysis. $p$-value $<0.05$ was considered significant.

\section{Follow up}

Patients visited the outpatient department every three months for the first two years and every six months thereafter. Clinical examination, liver function test, tumour markers, and ultrasound of the abdomen were advised at every visit. CECT and/ or 18-fluorodeoxyglucose positron emission tomography-computed tomography were advised selectively.

\section{RESULTS}

Out of a total of 161 patients who received EC during the study period, 75 patients were offered ECW and 86 patients were offered ECB. After excluding those with T1 tumors, T4 tumors, or benign pathologies, 102 patients $(\mathrm{ECW}=44, \mathrm{ECB}$ = 58) had T2 and T3 stage tumors. After matching, there were 35 patients in each group (Fig. 1). All patients had R0 resection. This section will focus on post-matching data. As depicted in Table 1, most of demographic, clinical, and laboratory parameters were comparable between the two groups except that for the use of the laparoscopic approach was more frequent in the ECB group $(p=0.000)$. For ECB vs. ECW, hospital stay was 6 days vs. 8 days $(p=0.216)$, operation time was 270 minutes vs. 300 minutes $(p=0.748)$, and surgical blood loss was $200 \mathrm{~mL}$ vs. $250 \mathrm{~mL}(p=0.005)$. The overall complication rate was $17.1 \%$ in the ECB group and $40.0 \%$ in the ECW group $(p=0.035)$. The incidence of grade II \& III complications and bile leak were significantly less in the ECB group $(p=0.002)$ (Table 2).

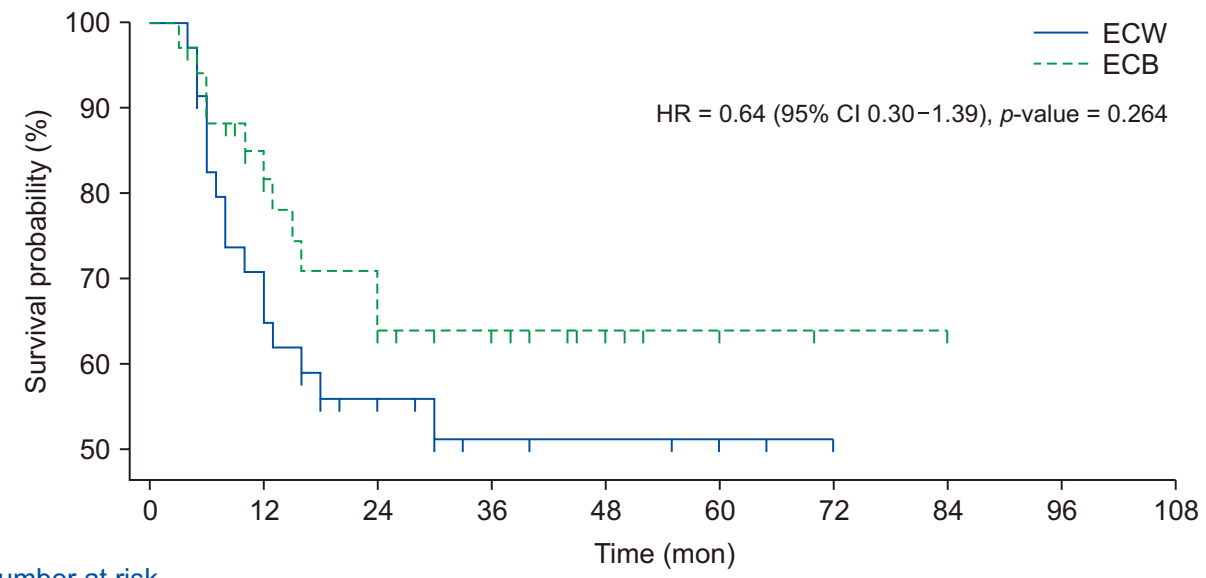

Number at risk

\begin{tabular}{|c|c|c|c|c|c|c|c|c|}
\hline Group: ECB & 22 & 13 & 8 & 5 & 2 & 0 & 0 & 0 \\
\hline 35 & 23 & 17 & 13 & 6 & 2 & 1 & 0 & 0 \\
\hline
\end{tabular}

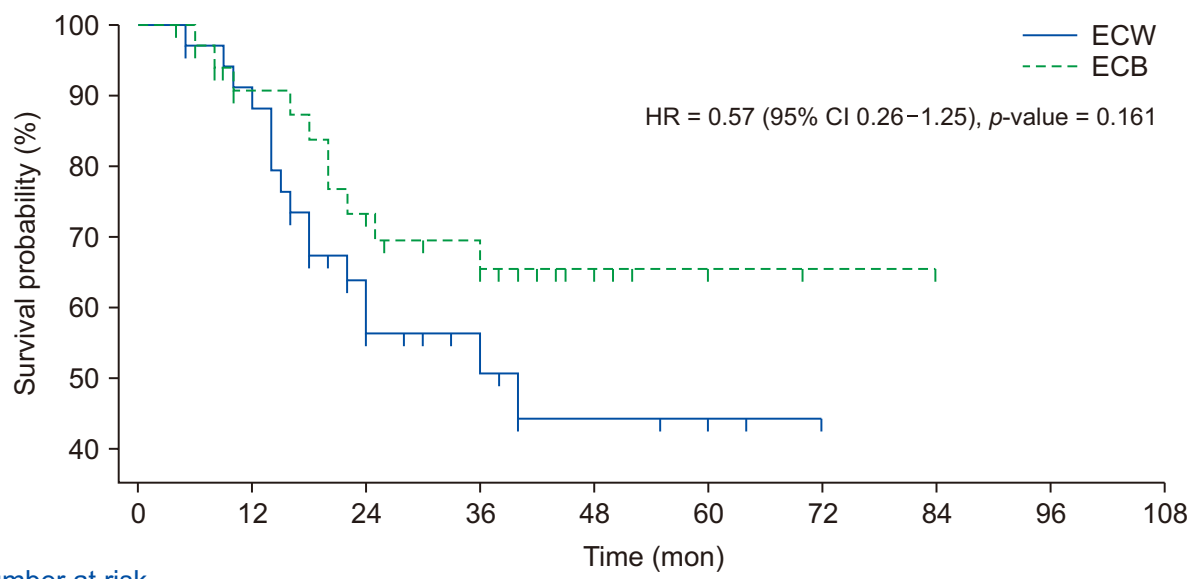

Number at risk Group: ECW

Group: ECB
30

26

$$
14
$$

20

9
14

5

2

2

$\begin{array}{lll}0 & 0 & 0 \\ 1 & 0 & 0\end{array}$

Fig. 2. Kaplan-Meier recurrence-free survival curves for ECB and ECW groups. $E C B$, extended cholecystectomy involving bi-segmentectomy s4b\&5; ECW, extended cholecystectomy involving wedge hepatic resection; $\mathrm{HR}$, hazard ratio; $\mathrm{Cl}$, confidence interval.
Fig. 3. Kaplan-Meier overall survival curves for ECB and ECW groups. ECB, extended cholecystectomy involving bisegmentectomy $s 4 b \& 5$; ECW, extended cholecystectomy involving wedge hepatic resection; $\mathrm{HR}$, hazard ratio; $\mathrm{Cl}$, confidence interval. 
Distributions of patients according to T, N, and AJCC stages were similar in both groups (Table 2). The minimum hepatic margin was $12 \mathrm{~mm}$ in the ECB group and $9 \mathrm{~mm}$ in the ECW group ( $p=0.487)$. In ECB and ECW groups, $65.7 \%$ and $62.9 \%$ of patients received adjuvant chemotherapy, respectively ( $p=$ 0.804 ). The recurrence rate was $31.4 \%$ in the ECB group and $45.7 \%$ in the ECW group (Table 2). Isolated hepatic recurrence was observed in four patients (3 in ECW group and 1 in ECB group). In the rest of patients, recurrence involved the liver, lymph nodes, and other organs simultaneously. Mean recurrence-free survival (RFS) was 58.2 months for the ECB group and 42.3 months for the ECW group (hazard ratio [HR]: 0.64, $95 \%$ confidence interval [CI]: $0.30-1.39, p=0.264$ ) (Table 2, Fig. 2). Mean overall survival (OS) was 61.5 months for the ECB group and 43.4 months for the ECW group (HR: 0.57, 95\% CI: $0.26-1.25 ; p=0.161$ ) (Table 2, Fig. 3). The probability of OS was $>50 \%$ for the ECB group. Therefore, median OS could not be estimated for ECB group. The median OS for the ECW group was 40 months (Table 2). One-year, 3-year, and 5-year RFS rates for ECB vs. ECW groups were $81.6 \%$ vs. $64.9 \%, 63.9 \%$ vs. $51.2 \%$, and $63.9 \%$ vs. $51.2 \%$, respectively. One-year, 3 -year, and 5-year OS rates for ECB vs. ECW groups were $90.8 \%$ vs. $88.3 \%, 65.6 \%$ vs. $50.8 \%$, and $65.6 \%$ vs. $44.4 \%$, respectively. The involvement of surrounding organs and the occurrence of various types of malignancies were comparable in both groups (Table 3). On univariate analysis, $\mathrm{T}$ stage and $\mathrm{N}$ stage were associated with poor prognosis. On multivariate analysis, $\mathrm{T}$ stage, $\mathrm{N}$ stage, and ASA grade were associated with poor RFS and OS (Table 3-5).

\section{DISCUSSION}

Anatomical location and drainage channels of the GB make segment $4 \mathrm{~b} \& 5$ of the liver most vulnerable to involvement by the GBC [1,15-18]. Previous studies have demonstrated that hepatic segment $4 \mathrm{~b} \& 5$ is the most common site of metastasis in early stage of GBC $[7,17,18]$. Shirai et al. $[19,20]$ have demon- strated a correlation between the extent of microscopic angiolymphatic portal tract invasion and gross depth of hepatic invasion by the GBC. It has been established that patients with positive resection margins have poorer outcomes than patients with negative resection margins [20]. An adequate extent of hepatic resection to clear microscopic metastatic foci and to achieve $\mathrm{R} 0$ resection is necessary to improve the survival of patients with resectable GBC [20-23]. In the present study, liver margins from the tumor were larger in the ECB group than in the ECW group. The minimum macroscopic liver margin aimed for the ECW group was about $2 \mathrm{~cm}(20 \mathrm{~mm})$. However, all patients had $\mathrm{R} 0$ resection.

Table 3. Comparison of tumor involvement and histological types

\begin{tabular}{lccc}
\hline \multicolumn{1}{c}{ Variable } & ECW $(\mathrm{n}=35)$ & $\mathrm{ECB}(\mathrm{n}=35)$ & $p$-value \\
\hline Site of tumor & & & 0.950 \\
Fundus alone & $10(40.0)$ & $13(44.8)$ & \\
Body alone & $5(20.0)$ & $3(10.3)$ & \\
Neck alone & $5(20.0)$ & $3(10.3)$ & \\
Fundus and body & $2(8.0)$ & $8(27.6)$ & \\
Body and neck & 0 & $2(6.9)$ & \\
Fundus, body and neck & $3(12.0)$ & 0 & 0.09 \\
Involvement of adjacent organs & & & 0.15 \\
Duodenal & $5(14.3)$ & $1(2.9)$ & 0.07 \\
Stomach & $2(5.7)$ & 0 & 0.30 \\
Common bile duct & $8(22.9)$ & $4(11.4)$ & 0.046 \\
Colon & $1(2.9)$ & $3(8.6)$ & \\
Tumor type & & & \\
Adenocarcinoma & $29(82.9)$ & $33(94.3)$ & \\
Adeno-squamous & $1(2.9)$ & $2(5.7)$ & \\
Intra cholecystic neoplasm & $3(8.6)$ & 0 & \\
Neuroendocrine tumor & $1(2.9)$ & 0 & \\
Squamous cell carcinoma & $1(2.9)$ & 0 & \\
\hline
\end{tabular}

Values are presented as number (\%).

$E C B$, extended cholecystectomy involving bi-segmentectomy s4b\&5; $\mathrm{ECW}$, extended cholecystectomy involving wedge hepatic resection.

Table 4. Cox proportional hazards analysis of prognostic factors for recurrence-free survival (matched population)

\begin{tabular}{|c|c|c|c|c|}
\hline \multirow{2}{*}{ Variable } & \multicolumn{2}{|c|}{ Univariate analysis } & \multicolumn{2}{|c|}{ Multivariable analysis } \\
\hline & Hazard ratio $(95 \% \mathrm{Cl})$ & $p$-value & Hazard ratio $(95 \% \mathrm{Cl})$ & $p$-value \\
\hline Age (> 50 vs. $\leq 50 \mathrm{yr}$ ) & $1.17(0.55-2.49)$ & 0.677 & & \\
\hline Sex (male vs. female) & $1.86(0.83-4.15)$ & 0.144 & & \\
\hline ASA grade 2,3 vs. 0,1 & $1.41(0.63-3.14)$ & 0.409 & $3.06(1.25-7.45)$ & 0.013 \\
\hline T stage (3 vs. 2 ) & $2.21(1.02-4.78)$ & 0.041 & $3.06(1.25-6.88)$ & 0.041 \\
\hline Node (positive vs. negative) & $14.80(4.3-50.3)$ & 0.000 & $21.35(5.64-80.83)$ & 0.000 \\
\hline Grade (poor vs. WD, MD) & $0.85(0.25-2.84)$ & 0.797 & & \\
\hline Resection (4b\&5 vs. wedge) & $0.65(0.30-1.40)$ & 0.270 & & \\
\hline Adjuvant therapy (yes vs. no) & $0.99(0.44-2.22)$ & 0.995 & & \\
\hline Postop complication (yes vs. no) & $1.15(0.51-2.57)$ & 0.727 & & \\
\hline
\end{tabular}

$\mathrm{Cl}$, confidence interval; ASA, American Society of Anaesthesiologists; poor, poorly differentiated; WD, well differentiated; MD, moderately differentiated. 
Hirdaya Hulas Nag, et al.

Table 5. Cox proportional hazards analysis of prognostic factors for overall survival (matched population)

\begin{tabular}{|c|c|c|c|c|}
\hline \multirow{2}{*}{ Variable } & \multicolumn{2}{|c|}{ Univariate analysis } & \multicolumn{2}{|c|}{ Multivariable analysis } \\
\hline & Hazard ratio $(95 \% \mathrm{Cl})$ & $p$-value & Hazard ratio $(95 \% \mathrm{Cl})$ & $p$-value \\
\hline Age (> 50 vs $\leq 50 \mathrm{yr})$ & $1.05(0.48-2.27)$ & 0.896 & & \\
\hline Sex (male vs. female) & $2.02(0.89-4.53)$ & 0.102 & & \\
\hline ASA grade 2,3 vs. 0,1 & $1.68(0.76-3.72)$ & 0.205 & $4.14(1.61-10.66)$ & 0.003 \\
\hline T stage $(3,4$ vs. 1,2$)$ & $2.79(1.24-6.28)$ & 0.010 & $3.17(1.16-8.62)$ & 0.023 \\
\hline Node (positive vs. negative) & $10.89(3.64-32.55)$ & 0.000 & $17.71(4.97-63.08)$ & 0.000 \\
\hline Grade (poor vs. WD, MD) & $0.96(0.28-3.20)$ & 0.948 & & \\
\hline Resection (4b\&5 vs. wedge) & $0.57(0.25-1.27)$ & 0.165 & & \\
\hline Adjuvant therapy (yes vs. no) & $1.13(0.49-2.60)$ & 0.770 & & \\
\hline Postop complication (yes vs. no) & $1.41(0.63-3.11)$ & 0.400 & & \\
\hline
\end{tabular}

$\mathrm{Cl}$, confidence interval; ASA, American Society of Anaesthesiologists; poor, poorly differentiated; WD, well differentiated; MD, moderately differentiated.

In the present study, tumor locations were similarly distributed between the two groups. However, patient selection for either ECB or ECW was not preferably decided on the basis of tumor location. It was mainly based on the extent of hepatic infiltration and the possibility of R0 resection with offered resection. Either extended right hepatectomy or segment 4, 5, \& 8 resection (whichever was appropriate to achieve R0 resection) was offered to patients with extensive hepatic infiltration or patients with tumor in close relation to the right anterior portal pedicle on CECT and such patients were excluded from this study.

In the present study, both disease-free survival and OS were longer for the ECB group, although differences between the two groups were not statistically significant. Similar results have been reported by two questionnaire surveys comparing ECB and ECW in patients with T2 GBC $[9,10]$. There were less surgical blood loss and postoperative complications in the ECB group than in the ECW group, reflecting more perfect control of portal pedicle in ECB [1]. However, other authors have reported more blood loss and bile leak with ECB [10]. The possible reason for significantly lower amount of blood loss in the ECB group might be a higher number of patients with laparoscopic approach in the ECB group, better portal pedicle control in the ECB group, and our practice of minimum use of Pringle's manoeuvre during hepatic transection. Recurrence rate was similar in both groups. Sole hepatic involvement was not common. Therefore, other factors such as AJCC stage are more likely to be the cause of recurrence other than the type of hepatic recurrence if $\mathrm{R} 0$ resection has been achieved [1,9,10,17,24].

Adjuvant chemotherapy might have yielded a positive impact on our results, although the percentage of patients with adjuvant chemotherapy was similar in both groups $[25,26]$. Our study was prone to biases due to its retrospective nature. Therefore, we matched our patients for $\mathrm{T}$ and $\mathrm{N}$ stages. Laparoscopic control of intra-operative bleeding is a tedious and tiring process. A subconscious thought that an early control of portal pedicle could have better outcome for controlling bleed- ing might have biased us to perform ECB while attempting laparoscopic EC. The prevalence of laparoscopic procedures in the ECB group might have some effects on our results. However, we could not match our patients for the laparoscopic approach because very few patients in the ECW group were managed with this approach due to more frequent use of ECB with a laparoscopic approach. Similar results of laparoscopic and open surgical management of patients with GBC have been reported previously $[27,28]$.

Our study may be criticised for not doing a subgroup analysis for patients with T2a and T2b GBC. As discussed earlier, we avoided this due to a high prevalence of IGBC in both groups as most of these patients with IGBC did not undergo a preoperative (pre-cholecystectomy) CECT necessary for this sub-classification.

In conclusion, the overall or recurrence free survival after ECB for T2 and T3 GBC was not significantly superior to that after ECW, although surgical blood loss and postoperative complications were lower following ECB.

\section{CONFLICT OF INTEREST}

No potential conflict of interest relevant to this article was reported.

\section{ORCID}

Hirdaya Hulas Nag, https://orcid.org/0000-0002-0194-7752

Phani Kumar Nekarakanti, https://orcid.org/0000-0002-4799-2081

Ashish Sachan, https://orcid.org/0000-0003-0673-8594

Prithviraj Nabi, https://orcid.org/0000-0002-1118-8454

Sonam Tyagi, https://orcid.org/0000-0002-2112-8834

\section{AUTHOR CONTRIBUTIONS}

Conceptulization: HHN. Data curation: All authors. Formal analysis: HHN, PKN, AS. Writing- original draft: HHN, PKN. 
Writing- review \& editing: All authors.

\section{REFERENCES}

1. Jarnagin WR, Allen PJ, Chapman WC, D’Angelica MI, DeMatteo RP, Gian RK, et al. Blumgart's surgery of the liver, biliary tract and pancreas. 6th ed. Philadelphia: Elsevier, 2017:786-804.

2. Boerma EJ. Towards an oncological resection of gall bladder cancer. Eur J Surg Oncol 1994;20:537-544.

3. Yoshikawa T, Araida T, Azuma T, Takasaki K. Bisubsegmental liver resection for gallbladder cancer. Hepatogastroenterology 1998;45:1419.

4. Reddy SK, Marroquin CE, Kuo PC, Pappas TN, Clary BM. Extended hepatic resection for gallbladder cancer. Am J Surg 2007;194:355-361.

5. Benson AB 3rd, Abrams TA, Ben-Josef E, Bloomston PM, Botha JF, Clary BM, et al. NCCN clinical practice guidelines in oncology: hepatobiliary cancers. J Natl Compr Canc Netw 2009;7:350-391.

6. Ohtsuka M, Miyazaki M, Itoh H, Nakagawa K, Ambiru S, Shimizu $\mathrm{H}$, et al. Routes of hepatic metastasis of gallbladder carcinoma. Am J Clin Pathol 1998;109:62-68.

7. Endo I, Takimoto A, Fujii Y, Togo S, Shimada H. [Hepatic resection for advanced carcinoma of the gallbladder]. Nihon Geka Gakkai Zasshi 1998;99:711-716. Japanese.

8. Suzuki M, Yamamoto K, Unno M, Katayose Y, Endo K, Oikawa M, et al. Detection of perfusion areas of the gallbladder vein on computed tomography during arterial portography (CTAP)--the background for dual S4a.S5 hepatic subsegmentectomy in advanced gallbladder carcinoma. Hepatogastroenterology 2000;47:631-635.

9. Araida T, Higuchi R, Hamano M, Kodera Y, Takeshita N, Ota T, et al. Hepatic resection in $485 \mathrm{R} 0 \mathrm{pT} 2$ and $\mathrm{pT} 3$ cases of advanced carcinoma of the gallbladder: results of a Japanese Society of Biliary Surgery survey--a multicenter study. J Hepatobiliary Pancreat Surg 2009;16:204-215.

10. Horiguchi A, Miyakawa S, Ishihara S, Miyazaki M, Ohtsuka M, Shimizu H, et al. Gallbladder bed resection or hepatectomy of segments 4a and 5 for pT2 gallbladder carcinoma: analysis of Japanese registration cases by the study group for biliary surgery of the Japanese Society of Hepato-Biliary-Pancreatic Surgery. J Hepatobiliary Pancreat Sci 2013;20:518-524.

11. Medical Council of India. Indian Medical Council (Professional Conduct, Etiquette and Ethics) regulations, 2002 [Internet]. New Delhi: Medical Council of India 2002 [cited 2006 Mar 25]. Available from: https://www.nmc.org.in/rules-regulations/code-of-medical-ethics-regulations-2002/.

12. Amin MB, Edge SB, Greene FL, Byrd DR, Brookland RK, Washington MK, et al. AJCC cancer staging manual. 8th ed. New York: Springer, 2017:303-309.

13. Dindo D, Demartines N, Clavien PA. Classification of surgical complications: a new proposal with evaluation in a cohort of 6336 patients and results of a survey. Ann Surg 2004;240:205-213.

14. Nag HH, Raj P, Sisodia K. The technique of laparoscopic hepatic bisegmentectomy with regional lymphadenectomy for gallbladder cancer. J Minim Access Surg 2018;14:124-129.

15. Uesaka K, Yasui K, Morimoto T, Torii A, Yamamura Y, Kodera Y, et al. Visualization of routes of lymphatic drainage of the gallbladder with a carbon particle suspension. J Am Coll Surg 1996;183:345-350.

16. Yoshimitsu K, Honda H, Kaneko K, Kuroiwa T, Irie H, Chijiiwa K, et al. Anatomy and clinical importance of cholecystic venous drainage: helical CT observations during injection of contrast medium into the cholecystic artery. AJR Am J Roentgenol 1997;169:505-510.

17. Yoshimitsu K, Honda H, Kuroiwa T, Irie H, Aibe H, Tajima T, et al. Liver metastasis from gallbladder carcinoma: anatomic correlation with cholecystic venous drainage demonstrated by helical computed tomography during injection of contrast medium in the cholecystic artery. Cancer 2001;92:340-348.

18. Endo I, Shimada H, Takimoto A, Fujii Y, Miura Y, Sugita M, et al. Microscopic liver metastasis: prognostic factor for patients with pT2 gallbladder carcinoma. World J Surg 2004;28:692-696.

19. Shirai Y, Tsukada K, Ohtani T, Watanabe H, Hatakeyama K. Hepatic metastases from carcinoma of the gallbladder. Cancer 1995;75:20632068.

20. Shirai Y, Yoshida K, Tsukada K, Muto T, Watanabe H. Radical surgery for gallbladder carcinoma. Long-term results. Ann Surg 1992;216:565-568.

21. Chijiiwa K, Nakano K, Ueda J, Noshiro H, Nagai E, Yamaguchi K, et al. Surgical treatment of patients with T2 gallbladder carcinoma invading the subserosal layer. J Am Coll Surg 2001;192:600-607.

22. Kai M, Chijiiwa K, Ohuchida J, Nagano M, Hiyoshi M, Kondo K. A curative resection improves the postoperative survival rate even in patients with advanced gallbladder carcinoma. J Gastrointest Surg 2007;11:1025-1032.

23. Wakai T, Shirai Y, Sakata J, Nagahashi M, Ajioka Y, Hatakeyama K. Mode of hepatic spread from gallbladder carcinoma: an immunohistochemical analysis of 42 hepatectomized specimens. Am J Surg Pathol 2010;34:65-74.

24. D’Angelica M, Dalal KM, DeMatteo RP, Fong Y, Blumgart LH, Jarnagin WR. Analysis of the extent of resection for adenocarcinoma of the gallbladder. Ann Surg Oncol 2009;16:806-816.

25. Ma N, Cheng H, Qin B, Zhong R, Wang B. Adjuvant therapy in the treatment of gallbladder cancer: a meta-analysis. BMC Cancer 2015;15:615.

26. Kasumova GG, Tabatabaie O, Najarian RM, Callery MP, Ng SC, Bullock AJ, et al. Surgical management of gallbladder cancer: simple versus extended cholecystectomy and the role of adjuvant therapy. Ann Surg 2017;266:625-631.

27. Jang JY, Han HS, Yoon YS, Cho JY, Choi Y. Retrospective comparison of outcomes of laparoscopic and open surgery for T2 gallbladder cancer - thirteen-year experience. Surg Oncol 2019;29:142-147.

28. Nag HH, Sachan A, Nekarakanti PK. Laparoscopic versus open extended cholecystectomy with bi-segmentectomy ( $44 \mathrm{~b}$ and s5) in patients with gallbladder cancer. J Minim Access Surg 2021;17:21-27. 